\title{
Social Deficits and Autism Spectrum Disorders in Tourette's Syndrome
}

\author{
Camille E. Hanks ${ }^{1}$ - Adam B. Lewin ${ }^{1,2,3}$ - P. Jane Mutch ${ }^{1}$ • Eric A. Storch ${ }^{1,2,3,4,5}$. \\ Tanya K. Murphy ${ }^{1,3,5}$
}

Published online: 15 August 2015

(C) Springer International Publishing Switzerland 2015

\begin{abstract}
Chronic tic disorders, including Tourette's syndrome (TS), are neuropsychiatric disorders characterized by the childhood onset of motor and/or vocal tics. Youth with TS often experience disturbances in social functioning, which can negatively impact functioning and overall quality of life. We summarize the existing knowledge about social deficits in youth with TS, while highlighting the various ways that these deficits present in comorbid developmental disorders (i.e., autism spectrum disorders) as well as in other TS-related phenomenology impacting social functioning (i.e., comorbid psychiatric conditions, tic severity, and peer victimization). Further, we discuss how interventions for TS should aim to address not only tic severity, but also the multifaceted reasons for social deficits within this population. We conclude with a discussion of clinical implications and future directions for clinical intervention and research.
\end{abstract}

This article is part of the Topical Collection on Tourette's Syndrome

Tanya K. Murphy

tmurphy@health.usf.edu

1 Department of Pediatrics, University of South Florida, 880 6th Street South, Suite 460, Box 7523, St. Petersburg, FL 33701, USA

2 Department of Psychology, University of South Florida, St. Petersburg, FL, USA

3 Departments of Psychiatry and Behavioral Neurosciences, University of South Florida, St. Petersburg, FL, USA

4 Department of Health Policy and Management, University of South Florida, Tampa, FL, USA

5 All Children's Hospital-Johns Hopkins Medicine, St. Petersburg, FL, USA
Keywords Tourette's syndrome $\cdot$ Chronic tic disorders · Tic disorders $\cdot$ Autism spectrum disorders $\cdot$ Social deficits $\cdot$ Peer victimization

\section{Introduction}

Tourette's syndrome (TS) is a neuropsychiatric disorder characterized by the childhood onset of multiple motor tics and at least one vocal tic for duration of at least 1 year [1]. TS impacts approximately $1-10$ in 1000 children [2-4] and is commonly associated with other psychiatric disorders including attention deficit hyperactivity disorder (ADHD) [5-7], obsessive-compulsive disorder (OCD) [6], mood disturbances $[8,9]$, disruptive behaviors [10], and learning disorders [11]. In addition, youth with TS often experience peer victimization $[12,13 \bullet]$, self-concept deficits [14•], and interpersonal difficulties $[15,16 \bullet]$, particularly those with comorbid autism spectrum disorders (ASD) [17, 18]. The compounding burden of these co-occurring conditions is often reported as more problematic than the tics themselves $[16 \bullet, 19,20]$.

Over the last few decades, researchers have increasingly examined the prevalence, development, maintenance, and treatment of social deficits among youth with TS. Broadly, social deficits are considered maladaptive behaviors that can include difficulty identifying social cues, difficulty with social engagement (or motivation), social communication, limited insight into other's feelings and intentions, and/or restricted or bizarre interests [21]. Dysfunction in these social domains can impact a child's ability to function in multiple settings (home and school) and can contribute to decreases in overall quality of life [16•]. Improving our understanding of the clinical characteristics and biological underpinnings of social deficits in youth with TS may help inform evidenced-based intervention strategies that will not only improve tic symptoms 
but also address these social deficits, bolstering improved quality of life and social acceptability of the disorder. This paper will review the literature as it pertains to the manifestation of social deficits in children and adolescents with TS through comorbid developmental disorders (i.e., ASD) and through other TS-related phenomenology and/or environmental factors that impact social functioning (i.e., tic severity, peer victimization, co-occurring psychopathology).

\section{TS and Autism Spectrum Disorders (ASD)}

In recent years, there has been an increasing interest in the clinical characteristics and biological underpinnings of TS and common co-occurring psychopathology, including ASD. Although there is no enough evidence to support a unified theory, recent research has focused on both genetic and neuropathological etiologies of TS and ASD. ASDs are neurodevelopmental disorders characterized by the presence of impaired social interaction and communication, typically accompanied by restricted interests and/or stereotyped behaviors. A recent epidemiological study estimated the global prevalence of ASD to be between 1 and $2 \%$ [22]. To date, numerous reports have examined the relationship between ASD and TS [17, 18, 23-29], including several populationbased studies identifying a significant relationship between TS and ASD above and beyond what would be expected by chance $[17,30,31]$. However, highly variable rates of comorbidity between tic disorders and ASD have been reported, ranging from 2.9 to $30.0 \%[6,9,16 \cdot, 30-32]$. This range of incidence rates may be attributed to variable clinical samples (e.g., severity of psychopathology, cognitive abilities) and/or differences in research methodology (e.g., utilization of treatment-seeking clinical samples versus population-based samples).

Initial Case Reports and Case Series The association between ASD and tic disorders was initially described in single case reports [33-37], including several describing the development of tics following withdrawal from long-term neuroleptics [38-41]. It is unclear, however, whether the neuroleptic medication use produced TS-like symptoms, or inadvertently masked tics that would have already been in existence. These early reports were followed by several case series presenting an elevated concurrence of ASD and TS [29, 42-45], as well as examples of tic development positively impacting autistic symptoms in several young children (mostly males) [24]. Collectively, these early reports spurred a growing interest and discussion in regards to the potential genetic overlap between the two disorders.

Larger Studies A consistent limitation in studies reporting overlap between ASD and TS has been capturing large cohorts of TS and/or ASD subjects. In 1999, Baron-Cohen and colleagues identified $8.1 \%$ of 37 school-aged children with autism presenting with comorbid TS [32]. Later, Canitano et al. [18] evaluated a clinical sample of 105 children with ASD, observing $22 \%$ with a tic disorder (11\% with TS and $11 \%$ with chronic motor tics) [18]. These findings suggested that the rate of comorbidity was higher than what would have been expected by chance; however, in both reports, the small sample size limited the generalizability of findings. Recently, the Tourette Syndrome International Consortium was initiated to more accurately describe the comorbidity patterns of TS using a large cohort of individuals. Using these data, Burd et al. [30] observed that $4.6 \%$ of the 7288 participants with TS presented with a comorbid pervasive development disorder (PDD), providing significant support that TS increases the risk for PDD (including ASDs) 13-fold [30]. Further, the presence of TS and comorbid PDD significantly increased the risk of additional comorbid psychopathology (not including PDD), with nearly $98 \%$ presenting with one or more comorbidity versus $13.2 \%$ in the group with TS only [30]. These findings suggest that patients with TS and PDD/ ASD may present with a more complex diagnostic picture, likely demanding more comprehensive and intensive managed care.

Familial and Genetic Findings Several studies have identified a positive family history of TS and/or ASD in individuals presenting with both disorders concurrently $[18,29,30]$. In a clinical sample of 105 youth with ASD, Canitano et al. [18] observed a positive family history for tic disorders in $59.5 \%$ of youth presenting with ASD and comorbid TS [18]. Burd et al. [30] also identified an association between neuropsychiatric symptoms (including TS and ASD) and a deletion involving exons 4,5 , and 6 of the gene neuroligin 4 (NLGN4) in a family study [30]. To further delineate potential genetic associations between TS and ASD, Fernandez et al. [46•] examined gene copy number variants (CNVs) in individuals with TS $(n=460)$ compared to control subjects $(n=1131)$. While no significant increases in the number of de novo or transmitted rare CNVs were identified in TS subjects compared to controls, gene mapping within rare CNVs in TS subjects showed significant overlap with CNVs previously identified in individuals with ASD [7, 46॰]. Taken together, these findings reinforce the idea of a common pathogenetic mechanism and shared genetic risk between the two disorders [7].

Neuropathological Similarities Given the growing evidence suggesting an etiological overlap between TS and ASD, this relationship has been investigated by several researchers via psychopathological, neuropsychological, brain imaging, genetic, and clinical studies. A recent review by Kern et al. [47] observed several neuropsychological similarities between $\mathrm{TS}, \mathrm{ASD}$, and ADHD, highlighting that these disorders may 
be part of a broader neurodevelopmental illness spectrum (termed abnormal connectivity spectrum disorder [ACSD]), resulting from neural processes that cause long-range underconnectivity and short-range overconnectivity. These connectivity abnormalities may be related to neurotoxicity, neuroinflammation, excitotoxicity, sustained microglial activation, proinflammatory cytokines, toxic exposure, and oxidative stress [47]. Evidence also suggests that the severity of connectivity deficits is associated with symptom severity in TS, ASD, and ADHD [48]. Collectively, these data further support the hypothesis that these disorders, though separate, may share common risk factors or possibly etiology.

Similarities in Symptomology Beyond potential etiological similarities, phenotypic overlap exists between TS and ASD. First, there is a significant male predominance in both disorders (approximately 60-80\%) [2, 49]. Second, these disorders have many overlapping clinical symptoms, including social deficits, speech abnormalities (e.g., echolalia or palilalia), sensory abnormalities, obsessive-compulsive symptoms, and repetitive motor behaviors $[47,50]$. However, there are also significant differences between the two disorders. For example, speech abnormalities such as coprolalia may present in TS but are not characteristic of ASD symptomology. In TS, disordered movements present as motor and vocal tics (i.e., repetitive, sudden, brief, irregular, involuntary) while ASD patients often present with stereotypies (i.e., repetitive, ritualistic, rhythmical, purposeful). Further, rigidity and resistance to change, common features of ASD, are somewhat distinct from the classic obsessive symptoms that frequently co-occur with TS [51]. Specific differences between tics and stereotypies can usually be differentiated by a thorough and comprehensive clinical evaluation, providing an accurate differential diagnosis [52]. A comparison of TS and ASD characteristics is presented in Table 1.

\section{Factors Impacting the Development of Social Deficits in TS}

Social skills deficits and/or interference has been identified in youth with chronic tic disorders even in the absence of ASD $[2,15,16 \bullet, 19,53-55]$. Freeman et al. [19] examined 3500 youth with TS as part of an international populationbased study, with $20 \%$ reporting deficits in social skills. Similarly, Kadesjo and Gillberg [17] reported that almost two thirds of their school-aged TS sample $(N=$ 58) had major social interaction problems (e.g., described as being without a friend or had "empathy problems"), with only $14 \%$ described as having no major problems interacting with their peers [17].
Carter et al. [15] found that youth with TS and comorbid ADHD had significantly more social adaptation problems (as well as externalizing and internalizing behavior problems) than unaffected control subjects or youth with TS alone. Further, obsessive-compulsive symptom severity and disturbances in family functioning were significantly associated with deficits in social, behavioral, and emotional functioning among youth with TS, while increased tic symptom severity was not [15]. This finding was consistent with three reports $[16 \bullet, 54,56]$, but in contrast to several others identifying a positive association between increased tic severity and deficits in social/emotional functioning $[57,58]$. This discrepancy may be attributed to differences in sample characteristics (e.g., inclusion of youth with more severe oppositional behaviors [57]) or analytic methodology (e.g., findings dependent on medication status [58]).

Similarly, Sukhodolsky et al. [10] identified a significant relationship between the presence of TS and deficits in social functioning (e.g., having fewer friends, being rejected by peers, not meeting the demands of everyday life) when compared to control subjects. Youth with comorbid ADHD did not significantly differ from youth without ADHD in these domains; however, both groups were significantly different from the control group. Further, the presence of disruptive behaviors (e.g., parent-reported aggression and delinquency) was associated with increased social deficits and family dysfunction [10]. These findings are consistent with previous studies reporting that aggressive behavior has the most detrimental effect on peer relationship difficulties in non-TS school-aged youth [59] and in youth with ADHD [60]. Storch et al. [19] examined the impact of TS on youth using a parent-report measure of functional impairment. In general, tic-related impairment in a least one domain (school, home, social activities) was reported by $70 \%$ of parents, with $42 \%$ reporting at least one significant problem interacting socially (e.g., problems making friends [21\%] or being around strangers [15\%]) [19]. In an Internet-based survey conducted by Conelea et al. [54], parents and youth with TS reported significant social interference due to symptoms, which was positively associated with tic severity and the presence of psychiatric comorbidities [54].

More recently, McGuire et al. [16•] found that youth with TS or chronic tic disorders $(N=99)$ had increased social deficits (e.g., difficulties picking up social cues, interpreting social cues, engagement in reciprocal social behavior) compared to normative samples, with $19 \%$ of TS youth exhibiting severe social deficits. Although the presence of ADHD (without comorbid OCD) and/or increased tic severity was not directly associated with social deficits, a positive relationship was identified between increased social impairment and the severity of inattention, hyperactivity, and oppositionality [16•]. Similarly, Ghanizadeh and Mosallaei [6] observed a significant proportion of TS youth with comorbid disruptive 
Table 1 Comparison of Tourette's syndrome (TS) and autism spectrum disorder (ASD) characteristics

\begin{tabular}{|c|c|c|c|}
\hline & TS & ASD & Ref \\
\hline \multicolumn{4}{|l|}{ General presentation } \\
\hline Male/female ratio & $2-3: 1$ & $3-4: 1$ & {$[73,79]$} \\
\hline Age of onset & $5-7$ years & $1-4$ years & {$[80]$} \\
\hline Lifetime prevalence & $0.1-1 \%$ & $1-2 \%$ & [22] \\
\hline \multicolumn{4}{|l|}{ Clinical symptoms } \\
\hline Attention deficit hyperactivity disorder & $50-80 \%$ & $31-34 \%$ & {$[9,73,81]$} \\
\hline Obsessive-compulsive disorder & $20-60 \%$ & $17-37 \%$ & {$[73,81]$} \\
\hline Anxiety disorder & $\sim 30 \%$ & $40-50 \%$ & {$[2,81,82]$} \\
\hline Sleep problems & $20-60 \%$ & $50-80 \%$ & {$[9,80,83]$} \\
\hline Repetitive motor movements & $\begin{array}{l}\text { Tics } \\
\text { - Onset } ~ 5-7 \text { years } \\
\text { - Premonitory urge } \\
\text { - Commonly in face, neck } \\
\text { - Sudden, non-rhythmic } \\
\text { - Can be suppressed } \\
\text {-Unwanted by individual }\end{array}$ & $\begin{array}{l}\text { Stereotypies } \\
\text { - Onset } \sim 1-4 \text { years } \\
\text { - No premonitory urge } \\
\text { - Commonly in arms, hands } \\
\text { - Prolonged, rhythmic } \\
\text { - Not typically suppressed } \\
\text { - May be viewed positively by individual }\end{array}$ & {$[52,80]$} \\
\hline
\end{tabular}

behavioral disorders exhibiting greater parent-reported social problems compared to youth without these cooccurring behaviors [6]. These data are consistent with existing literature describing significant social impairment in youth with ADHD and/or commonly comorbid disruptive behavior (with or without TS) [61]. Taken together, these findings highlight the increased prevalence of social deficits among individuals with TS and highlight the impact of comorbid psychiatric diagnoses (particularly ADHD), disruptive behaviors, and/or increased tic severity on social functioning.

\section{Peer Relationship Problems in TS}

In addition to the social deficits often reported in samples of youth with TS, a few reports have also shed light on the peer relationship problems that these youth often experience. Previous findings suggest that youth with TS are viewed as more socially withdrawn and less popular than their peers [56, 62], have difficulty getting along with their classmates [63], and experience increased bullying or victimization by their peers compared to youth with other chronic health conditions (type 1 diabetes) or healthy controls $[12,13 \bullet, 64]$. Evidence also suggests that peer victimization experienced by youth with TS is positively associated with increased tic symptom severity, strength of premonitory urge, loneliness, internalizing symptoms (e.g., anxiety and/or depression), explosive outbursts, and deficits in quality of life $[12,13 \cdot]$. Peer victimization was also identified as a mediator between tic symptom severity and loneliness [12], suggesting that victimized youth may perceive negative peer evaluations as veridical information about themselves which can negatively shape their self-concept and foster greater internalizing distress $[14 \cdot, 65,66]$.

\section{Social Deficits in Adults with TS}

Although TS symptoms tend to decrease or remit once a child reaches late adolescence, a considerable portion of individuals exhibit tics into adulthood [67]. Previous research suggests that social deficits in youth with TS may carry over into adulthood as well [68-70]. In a survey-based assessment of social functioning in individuals with TS, Champion, Fulton, and Shady [69] found that almost half of the adults within their total sample $(N=210)$ reported significant problems with dating as a result of their TS symptoms. This finding is consistent with an earlier study reporting low marriage rates in adults with TS [70]. Further, Shady et al. [68] found that adults with TS reported significant interpersonal problems in the workplace, including experiencing ridicule by coworkers and/or employers about their tics, low job satisfaction, and discrimination in the workplace [68]. More recently, Conelea et al. [71] conducted an Internet-based survey of 1216 adults with TS to assess the impact of tics on functioning, finding that a significant portion of the sample reported avoidance of social situations and/or experienced discrimination due to their tics. Further, from the adults employed within the last 12 months of the study ( $n=461)$, a significant portion of the sample avoided pursuing a job promotion (12\%) or avoided a job interview $(11.9 \%)$ because of their tics, both of which positively correlated with tic severity [71]. Evidence suggests that women may also be at greater risk for tic-related social impairment 
and avoidance of social/group activities compared to men, independent of tic severity [72].

\section{Evidence-Based Interventions for Improving Social Functioning in TS}

Although substantial evidence exists for pharmacological and behavioral interventions for tics [73], there is a paucity of research evaluating the effectiveness of augmenting (or modifying) interventions to address social deficits within this population. Youth with tics may benefit from social skills training to improve peer relationships and/or effectively respond to teasing or rejection [74]. Educating youth and parents about the greater social and emotional risks associated with their condition and monitoring family functioning (e.g., stress related to chronic condition) in combination with evidencedbased pharmacologic and/or behavioral treatments may also be beneficial. Careful assessment should be done to examine tic-related impairment on an individual basis, rather than assuming that all youth with TS have similar problems [19].

Peer-Focused Interventions Recently, researchers have investigated TS intervention strategies that aim to improve the social acceptability of the disorder, including self-disclosure of diagnosis and/or educational outreach via video-based delivery. To date, there have been at least five studies evaluating these interventions. First, Woods [75] randomly assigned subjects to a group that either received an educational video about TS or no video; then, all subjects watched an hour long video of an actor portraying a person with TS. Their findings indicated that subjects who watched the educational video were more likely to positively rate the actor in regards to social acceptability than those that did not watch the video [75]. In a follow-up study, Woods and Marcks [76] compared groups receiving either an educational video about TS, a similar video about depression, or no video. Only subjects receiving the TSspecific video demonstrated increased acceptability of TS, indicating that this increase was not solely an effect of educational videos about mental health challenges [76]. Third, Marcks et al. [37] found that the preventative self-disclosure (compared to nondisclosure) of TS symptoms significantly reduced negative perceptions of an individual with TS, regardless of gender or age. Fourth, Holtz and Tessman [77] found that compared to a control group, youth exposed to a videobased educational tool exhibited significant changes in knowledge, positive attitudes, and behavioral intentions toward their peers with TS [77]. More recently, the effect of either generic TS educational videos or personally delivered self-disclosure on participant's perceptions of individuals with TS was compared. Although both conditions rated their knowledge about tics significantly higher than those who did not watch any video, those who viewed the actor personally self-disclose their symptoms had higher ratings of social acceptability than those in the generic TS education video [78]. Taken together, these findings suggest that increasing TS awareness, especially when information is personally self-disclosed by those with TS, can significantly improve the social acceptability of individuals with TS.

\section{Conclusions}

Existing research suggests an increased prevalence of comorbid ASD and/or disturbances in social functioning and peer victimization among individuals with TS. While the precise nature of these relationships is uncertain, both genetic factors and co-occurring psychopathology have been implicated in the etiology and/or maintenance of these difficulties. Over the last few decades, researchers have identified several factors that may contribute to these social disturbances, highlighting the negative impact of comorbid psychiatric diagnoses (particularly ADHD), disruptive behaviors, and/or increased tic severity. Evidence also suggests that peer victimization experienced by youth with TS is associated with increased tic symptom severity, strength of premonitory urge, loneliness, internalizing symptoms (e.g., anxiety and/or depression), explosive outbursts, and deficits in quality of life. Although several studies postulate that reducing these disabling aspects of symptom presentations beyond tics will reduce the overall burden of TS, most are cross-sectional or preliminary in nature. As such, interventions for TS should aim to address not only tic severity, but also the multifaceted reasons for social deficits within this population.

\section{Compliance with Ethics Guidelines}

Conflict of Interest Camille E. Hanks and P. Jane Mutch declare that they have no conflict of interest.

Adam B. Lewin reports other from Children's Tumor Foundation, University of Central Oklahoma, Springer, Rogers Hospital, TSA, APA Division 53, and Oxford; personal fees from Prophase; and grants from All Childrens Hospital and IOCDF.

Eric A. Storch reports grants from National Institute of Health, Agency for Healthcare Research and Quality, Ortho-McNeil Janssen Scientific Affairs, Fulbright scholar program, All Children's Hospital Research Foundation, and International OCD Foundation; and book royalties from Wiley, Lawrence Erlbaum, Springer publishers, and American Psychological Association.

Tanya K. Murphy reports grants from AstraZeneca Pharmaceuticals, Auspex Pharmaceuticals, Sunovion Pharmaceuticals, Psyadon Pharmaceuticals, Pfizer, Inc., Neurocrine Biosciences, Hoffmann-La Roche Ltd., Shire Pharmaceuticals, Centers for Disease Control, National Institute of Mental Health, Massachusetts General Hospital, Otsuka Pharmaceuticals, and PANDAS Network; and personal fees from International OCD Foundation, Tourette Syndrome Association, and Grand Rounds/Continuing Medical. 
Human and Animal Rights and Informed Consent This article does not contain any studies with human or animal subjects performed by any of the authors.

\section{References}

Papers of particular interest, published recently, have been highlighted as:

- Of importance

1. American Psychiatric Association. Diagnostic and Statistic Manual of Mental Disorders. 5th ed. Arlington: American Psychiatric Publishing; 2013.

2. Freeman RD, Fast DK, Burd L, Kerbeshian J, Robertson MM, Sandor P. An international perspective on Tourette syndrome: selected findings from 3500 individuals in 22 countries. Dev Med Child Neurol. 2000;42(7):436-47.

3. Scahill L, Bitsko R, Visser S, Blumberg S. Centers for disease control: prevalence of diagnosed Tourette syndrome in persons aged 6-17 years - United States, 2007. Morb Mortal Wkly Rep. 2009;58(21):581-5.

4. Scharf JM, Miller LL, Mathews CA, Ben-Shlomo Y. Prevalence of Tourette syndrome and chronic tics in the population-based Avon longitudinal study of parents and children cohort. J Am Acad Child Adolesc Psychiatry. 2012;51(2):192-201. e5.

5. Freeman RD. Tourette syndrome international database consortium. Tic disorders and ADHD: answers from a world-wide clinical dataset on Tourette syndrome. Eur Child Adolesc Psychiatry. 2007;16(9):15-23.

6. Ghanizadeh A, Mosallaei S. Psychiatric disorders and behavioral problems in children and adolescents with Tourette syndrome. Brain Dev. 2009;31(1):15-9.

7. Roessner V, Becker A, Banaschewski T, Rothenberger A. Psychopathological profile in children with chronic tic disorder and co-existing ADHD: additive effects. J Abnorm Child Psychol. 2007;35(1):79-85.

8. Robertson MM. Mood disorders and Gilles de la Tourette's syndrome: an update on prevalence, etiology, comorbidity, clinical associations, and implications. J Psychosom Res. 2006;61(3):349-58.

9. Ferreira BR, Pio-Abreu J, Januário C. Tourette's syndrome and associated disorders: a systematic review. Trends Psychiatry Psychotherapy. 2014;36(3):123-33.

10. Sukhodolsky DG, Scahill L, Zhang H, Peterson BS, King RA, Lombroso PJ, et al. Disruptive behavior in children with Tourette's syndrome: association with ADHD comorbidity, tic severity, and functional impairment. J Am Acad Child Adolesc Psychiatry. 2003;42(1):98-105.

11. Burd L, Freeman RD, Klug MG, Kerbeshian J. Tourette syndrome and learning disabilities. BMC Pediatr. 2005;5(1):34.

12. Storch EA, Murphy TK, Chase RM, Keeley M, Goodman WK, Murray M, et al. Peer victimization in youth with Tourette's syndrome and chronic tic disorder: relations with tic severity and internalizing symptoms. J Psychopathol Behav. 2007;29(4):211-9.

13. Zinner SH, Conelea CA, Glew GM, Woods DW, Budman CL. Peer victimization in youth with Tourette syndrome and other chronic tic disorders. Child Psychiatry Hum Dev. 2012;43(1):124-36. An internet-based survey study of 211 children and their parents examined the impact of tic disorders on peer victimization, providing evidence that peer victimization may be associated with increased tic severity, stronger premonitory urges, worse quality of life, and elevated internalizing symptoms such as anxiety or depression.

14. Hanks CE, McGuire JF, Lewin AB, Storch EA, Murphy TK. Clinical correlates and mediators of self-concept in youth with chronic tic disorders. Child Psychiatry Hum Dev. 2015. doi:10. 1007/s10578-015-0544-0. Examined the clinical correlates and mediators of self-concept deficits among youth with chronic tic disorders (CTD), highlighting the negative impact of comorbid psychopathology on self-concept, particularly OCD and ADHD.

15. Carter AS, O'Donnell DA, Schultz RT, Scahill L, Leckman JF, Pauls DL. Social and emotional adjustment in children affected with Gilles de la Tourette's syndrome: associations with ADHD and family functioning. J Child Psychol Psychiatry. 2000;41(02): 215-23.

16. McGuire JF, Hanks C, Lewin AB, Storch EA, Murphy TK. Social deficits in children with chronic tic disorders: Phenomenology, clinical correlates and quality of life. Compr Psychiatry. 2013;54(7): 1023-31. Examined the presence and characteristics of social deficits in youth with chronic tic disorders (CTD), highlighting the increased social deficits exhibited by youth with CTD compared to normative samples, particularly those youth with more severe inattentiveness, hyperactivity, and oppositionality.

17. Kadesjö B, Gillberg C. Tourette's disorder: epidemiology and comorbidity in primary school children. J Am Acad Child Adolesc Psychiatry. 2000;39(5):548-55.

18. Canitano R, Vivanti G. Tics and Tourette syndrome in autism spectrum disorders. Autism. 2007;11(1):19-28.

19. Storch EA, Lack CW, Simons LE, Goodman WK, Murphy TK, Geffken GR. A measure of functional impairment in youth with Tourette's syndrome. J Pediatr Psychol. 2007;32(8):950-9.

20. Specht MW, Woods DW, Piacentini J, Scahill L, Wilhelm S, Peterson AL, et al. Clinical characteristics of children and adolescents with a primary tic disorder. J Dev Phys Disabil. 2011;23(1): $15-31$.

21. Constantino JN. The quantitative nature of autistic social impairment. Pediatr Res. 2011;69:55R-62.

22. Elsabbagh M, Divan G, Koh YJ, Kim YS, Kauchali S, Marcín C, et al. Global prevalence of autism and other pervasive developmental disorders. Autism Res. 2012;5(3):160-79.

23. Kerbeshian J, Burd L. Tourette syndrome and prognosis in autism. Eur Child Adolesc Psychiatry. 2003;12(2):103.

24. Zappella M. Early-onset Tourette syndrome with reversible autistic behaviour: a dysmaturational disorder. Eur Child Adolesc Psychiatry. 2002;11(1):18-23.

25. Cohen D. Into life: autism, Tourette's syndrome and the community of clinical research. Israel J Psychiatry Relat Sci. 2000;38(3-4): 226-34.

26. Rapin I. Autism spectrum disorders: relevance to Tourette syndrome. Adv Neurol. 2000;85:89-101.

27. Kerbeshian J, Severud R, Burd L, Larson L. Peek-a-boo fragile site at $16 \mathrm{~d}$ associated with Tourette syndrome, bipolar disorder, autistic disorder, and mental retardation. Am J Med Genet. 2000;96(1):69 73.

28. Kerbeshian J, Burd L. Case study: comorbidity among Tourette's syndrome, autistic disorder, and bipolar disorder. J Am Acad Child Adolesc Psychiatry. 1996;35(5):681-5.

29. Comings DE, Comings BG. Clinical and genetic relationships between autism-pervasive developmental disorder and Tourette syndrome: A study of 19 cases. Am J Med Genet. 1991;39(2):180-91.

30. Burd L, Li Q, Kerbeshian J, Klug MG, Freeman RD. Tourette syndrome and comorbid pervasive developmental disorders. J Child Neurol. 2009;24(2):170-5.

31. Simonoff E, Pickles A, Charman T, Chandler S, Loucas T, Baird G. Psychiatric disorders in children with autism spectrum disorders: prevalence, comorbidity, and associated factors in a population- 
derived sample. J Am Acad Child Adolesc Psychiatry. 2008;47(8): 921-9.

32. Baron-Cohen S, Mortimore C, Moriarty J, Izaguirre J, Robertson M. The prevalence of Gilles de la Tourette's syndrome in children and adolescents with autism. J Child Psychol Psychiatry. 1999;40(2):213-8.

33. Barabas G, Matthews WS. Coincident infantile autism and Tourette syndrome: a case report. J Dev Behav Pediatr. 1983;4(4):280-1.

34. Kano Y, Ohta M, Nagai Y, Yokota K, Shimizu Y. Tourette's disorder coupled with infantile autism: a prospective study of two boys. Psychiatry Clin Neurosci. 1988;42(1):49-57.

35. Realmuto GM, Main B. Coincidence of Tourette's disorder and infantile autism. J Autism Dev Disord. 1982;12(4):367-72.

36. Hebebrand J, Martin M, Körner J, Roitzheim B, de Braganca K, Werner W, et al. Partial trisomy 16p in an adolescent with autistic disorder and Tourette's syndrome. Am J Med Genet. 1994;54(3): 268-70.

37. Marcks BA, Berlin KS, Woods DW, Davies WH. Impact of Tourette Syndrome: a preliminary investigation of the effects of disclosure on peer perceptions and social functioning. Psychiatry. 2007;70(1):59-67.

38. Mueller J, Aminoff M. Tourette-like syndrome after long-term neuroleptic drug treatment. Brit J Psychiatry. 1982;141(2):191-3.

39. Stahl SM. Tardive Tourette syndrome in an autistic patient after long-term neuroleptic administration. Am J Psychiatry. 1980;137(10):1267-9.

40. Littlejohns CS, Clarke DJ, Corbett JA. Tourette-like disorder in Asperger's syndrome. Brit J Psychiatry. 1990;156(3):430-3.

41. Perry R, Nobler MS, Campbell M. Tourette-like symptoms associated with neuroleptic therapy in an autistic child. J Am Acad Child Adolesc Psychiatry. 1989;28(1):93-6.

42. Burd L, Fisher W, Kerbeshian J. A prevalence study of pervasive developmental disorders in North Dakota. J Am Acad Child Adolesc Psychiatry. 1987;26(5):700-3.

43. Sverd J, Montero G, Gurevich N. Brief report: cases for an association between Tourette syndrome, autistic disorder, and schizophrenia-like disorder. J Autism Dev Disord. 1993;23(2): 407-13.

44. Sverd J. Tourette syndrome and autistic disorder: a significant relationship. Am J Med Genet. 1991;39(2):173-9.

45. Marriage K, Miles T, Stokes D, Davey M. Clinical and research implications of the co-occurrence of Asperger's and Tourette syndromes. Aust N Z J Psychiatry. 1993;27(4):666-72.

46. Fernandez TV, Sanders SJ, Yurkiewicz IR, Ercan-Sencicek AG, Kim Y-S, Fishman DO, et al. Rare copy number variants in tourette syndrome disrupt genes in histaminergic pathways and overlap with autism. Biol Psychiatry. 2012;71(5):392-402. A recent casecontrol study examined rare copy number variations (CNVs) in TS and control youth, providing evidence to support the hypotheses that histaminergic and gamma-aminobutyric acidergic mechanisms are involved in the etiology of TS, as well as identifying significant overlap with CNVs in TS individuals previously identified in individuals with ASD.

47. Lewin AB, Wu MS, Murphy TK, Storch EA. Sensory overresponsivity in pediatric obsessive compulsive disorder. J Psychopathol Behav. 2015;37:134-43.

48. Cheng B, Braass H, Ganos C, Treszl A, Biermann-Ruben K, Hummel FC, et al. Altered intrahemispheric structural connectivity in Gilles de la Tourette syndrome. NeuroImage: Clin. 2014;4:174-81.

49. Leivonen S, Voutilainen A, Hinkka-Yli-Salomäki S, TimonenSoivio L, Chudal R, Gissler M, et al. A nationwide register study of the characteristics, incidence and validity of diagnosed Tourette syndrome and other tic disorders. Acta Paediatr. 2014;103(9):984-90.
50. Stern JS, Robertson MM. Tics associated with autistic and pervasive developmental disorders. Neurol Clin. 1997;15(2):345-55.

51. Ringman JM, Jankovic J. Occurrence of tics in Asperger's syndrome and autistic disorder. J Child Neurol. 2000;15(6):394-400.

52. Kurlan R. The differential diagnosis of tic disorders. In: Martino D, Leckman J, editors. Tourette Syndrome. New York: Oxford University Press; 2013. p. 395-401.

53. Kurlan R, Daragjati C, Como PG, McDermott MP, Trinidad KS, Roddy S, et al. Non-obscene complex socially inappropriate behavior in Tourette's syndrome. J Neuropsychiatry Clin Neurosci. 1996;8(3):311-7.

54. Conelea CA, Woods DW, Zinner SH, Budman C, Murphy T, Scahill LD, et al. Exploring the impact of chronic tic disorders on youth: results from the Tourette Syndrome Impact Survey. Child Psychiatry Hum Dev. 2011;42(2):219-42.

55. Packer LE. Tic-related school problems: impact on functioning, accommodations, and interventions. Behav Modif. 2005;29(6): 876-99.

56. Bawden HN, Stokes A, Carol S, Carol S, Camfield PR, Salisbury S. Peer relationship problems in children with Tourette's disorder or diabetes mellitus. J Child Psychol Psychiatry. 1998;39(5):663-8.

57. Nolan EE, Sverd J, Gadow KD, Sprafkin J, Ezor SN. Associated psychopathology in children with both ADHD and chronic tic disorder. J Am Acad Child Adolesc Psychiatry. 1996;35(12):1622-30.

58. Rosenberg LA, Brown J, Singer HS. Behavioral problems and severity of tics. J Clin Psychol. 1995;51(6):760-7.

59. Ladd GW, Burgess KB. Charting the relationship trajectories of aggressive, withdrawn, and aggressive/withdrawn children during early grade school. Child Dev. 1999;70(4):910-29.

60. Bagwell CL, Molina BS, Pelham WE, Hoza B. Attention-deficit hyperactivity disorder and problems in peer relations: predictions from childhood to adolescence. J Am Acad Child Adolesc Psychiatry. 2001;40(11):1285-92.

61. Nijmeijer JS, Minderaa RB, Buitelaar JK, Mulligan A, Hartman CA, Hoekstra PJ. Attention-deficit/hyperactivity disorder and social dysfunctioning. Clin Psychol Rev. 2008;28(4):692-708.

62. Stokes A, Bawden HN, Backman JE, Dooley JM, Camfield PR. Peer problems in Tourette's disorder. Pediatrics. 1991;87(6):93642.

63. Shady GA, Fulton WA, Champion LM. Tourette syndrome and educational problems in Canada. Neurosci Biobehav Rev. 1989;12(3):263-5.

64. Jagger J, Prusoff BA, Cohen DJ, Kidd KK, Carbonari CM, John K. The epidemiology of Tourette's syndrome. Schizophr Bull. 1982;8(2):267-78.

65. Grills AE, Ollendick TH. Peer victimization, global self-worth, and anxiety in middle school children. J Clin Child Adolesc Psychol. 2002;31(1):59-68.

66. Storch EA, Brassard MR, Masia-Warner CL. The relationship of peer victimization to social anxiety and loneliness in adolescence. Child Study J. 2003;33(1):1-18.

67. Goetz C, Tanner C, Stebbins G, Leipzig G, Carr W. Adult tics in Gilles de la Tourette's syndrome description and risk factors. Neurology. 1992;42(4):784-8.

68. Shady G, Broder R, Staley D, Furer P, Brezden PR. Tourette syndrome and employment: descriptors, predictors, and problems. Psychiatr Rehabil J. 1995;19(1):35.

69. Champion LM, Fulton WA, Shady GA. Tourette syndrome and social functioning in a Canadian population. Neurosci Biobehav Rev. 1989;12(3):255-7.

70. Shapiro AK, Shapiro E, Wayne H. Birth, developmental, and family histories and demographic information in Tourette's syndrome. J Nerv Ment Dis. 1972;115(5):335-44.

71. Conelea CA, Woods DW, Zinner SH, Budman CL, Murphy TK, Scahill LD, et al. The impact of Tourette syndrome in adults: results 
from the Tourette syndrome impact survey. Community Ment Health J. 2013;49(1):110-20.

72. Lewin AB, Murphy TK, Storch EA, Conelea CA, Woods DW, Scahill LD, et al. A phenomenological investigation of women with Tourette or other chronic tic disorders. Compr Psychiatry. 2012;53(5):525-34.

73. Murphy TK, Lewin AB, Storch EA, Stock S. Practice parameter for the assessment and treatment of children and adolescents with tic disorders. J Am Acad Child Adolesc Psychiatry. 2013;52(12): 1341-59.

74. McGuire JF, Arnold E, Park JM, Nadeau JM, Lewin AB, Murphy TK, et al. Living with tics: reduced impairment and improved quality of life for youth with chronic tic disorders. Psychiatry Res. 2015;225(3):571-9.

75. Woods DW. The effect of video-based peer education on the social acceptability of adults with Tourette's syndrome. J Dev Phys Disabil. 2002;14(1):51-62.

76. Woods DW, Marcks BA. Controlled evaluation of an educational intervention used to modify peer attitudes and behavior toward persons with Tourette's Syndrome. Behav Modif. 2005;29(6): 900-12.
77. Holtz KD, Tessman GK. Evaluation of a peer-focused intervention to increase knowledge and foster positive attitudes toward children with Tourette syndrome. J Dev Phys Disabil. 2007;19(6):531-42.

78. Olufs EL, Himle MB, Bradley AR. The effect of generic versus personally delivered education and self-disclosure on the social acceptability of adults with Tourette syndrome. J Dev Phys Disabil. 2013;25(4):395-403.

79. Fombonne E. Epidemiology of pervasive developmental disorders. Pediatr Res. 2009;65(6):591-8.

80. Nebel-Schwalm M, Worley J. Other Disorders Frequently Comorbid with Autism. In: Davis T, White S, Ollendick TH, editors. Handbook of Autism and Anxiety. Switzerland: Springer; 2014. p. 47-60.

81. Leyfer OT, Folstein SE, Bacalman S, Davis NO, Dinh E, Morgan J, et al. Comorbid psychiatric disorders in children with autism: interview development and rates of disorders. J Autism Dev Disord. 2006;36(7):849-61.

82. Ung D, Wood JJ, Ehrenreich-May J, Arnold EB, Fujii C, Renno P, et al. Clinical characteristics of high-functioning youth with autism spectrum disorder and anxiety. Neuropsychiatry. 2013;3(2):147-57.

83. Ghosh D, Rajan PV, Das D, Datta P, Rothner AD, Erenberg G. Sleep disorders in children with Tourette syndrome. Pediatr Neurol. 2014;51(1):31-5. 